\title{
Coupling Photo and Sono Technologies with BDD Anodic Oxidation for Treating Soil-Washing Effluent Polluted with Atrazine
}

\author{
E. Vieira dos Santos, ${ }^{1}$ C. Sáez, ${ }^{2}$ P. Cañizares, ${ }^{2}$ M. A. Rodrigo, ${ }^{2, z}$ \\ and C. A. Martínez-Huitle $\mathbb{1}^{3,4, a, z}$ \\ ${ }^{1}$ School of Science and Technology, Federal University of Rio Grande do Norte, 59078-970 Natal, Brazil \\ ${ }^{2}$ Department of Chemical Engineering, Enrique Costa Building, Universidad de Castilla-La Mancha, \\ Ciudad Real, Spain \\ ${ }^{3}$ Institute of Chemistry, Federal University of Rio Grande do Norte, Lagoa Nova, CEP 59078-970, Natal, RN, Brazil \\ ${ }^{4}$ Unesp, National Institute for Alternative Technologies of Detection, Toxicological Evaluation and Removal of \\ Micropollutants and Radioactives (INCT-DATREM), Institute of Chemistry, 14800-900 Araraquara (SP), Brazil
}

\begin{abstract}
In this work, it was studied the treatment of soil washing effluents coming from the remediation of a soil spiked with atrazine by using photolysis, sonolysis, electrolysis as well as photo- and sono- electrochemical technologies using diamond anodes. Results clearly showed that both irradiated technologies were more efficient than the single electrolytic technology and these can become a good alternative for the treatment of these effluents. Main characteristic of the effluents produced in the soil washing depended strongly on the ratio surfactant/soil. And, as a novel catalytic effect, the production of persulfate from the sulfate released during the oxidation of SDS played an important role in the oxidation mechanisms of this type of pollutants. Then, SDS can be proposed as an auxiliary reagent to be introduced in the effluent when emulsion is present to increase the efficiency of the electrochemical approach used.
\end{abstract}

(C) 2018 The Electrochemical Society. [DOI: 10.1149/2.1281805jes]

Manuscript submitted January 3, 2018; revised manuscript received March 29, 2018. Published April 18, 2018.

Pesticides are very useful compounds in agriculture which help to increase productivity but at the same time they are hazardous for human health and the environment and so, their occurrence in wastewater should be prevented. ${ }^{1}$ Amongst the various pesticides that have been studied with a view to develop alternative and environmentally acceptable treatment systems, atrazine has received considerable attention. ${ }^{2}$

Atrazine is frequently used, in combination with other herbicides, for combating grassy and broadleaf weeds in corn, sorghum, sugarcane crops and rangeland. ${ }^{3}$ In wastewater, this herbicide becomes a typical persistent organic pollutant because of its low biodegradability, long half-life and high solubility in water $\left(33 \mathrm{mg} \mathrm{dm}^{-3}\right.$ at $\left.22^{\circ} \mathrm{C}\right)$. In some Latin-American countries, atrazine is the most widely used herbicide, while it was banned in USA and Europe because several metabolites of atrazine oxidation are more persistent in water and their occurrence is more often than the initial molecule. ${ }^{3,4}$

Many works have been published during the last years about the elimination of atrazine from water sources ${ }^{5-17}$ (e.g.: adsorption, anodic oxidation, electro-Fenton, photo-assisted electrochemical oxidation, ozonation and solar photodegradation), achieving significant insights in effective destruction of this very persistent pollutant. However, the pollution of soil through atrazine accumulation is also feasible when the aquatic eco-system is not treated or when the percolation of contaminated surface water to subsurface strata occurs. Therefore, the combination of electrochemical approaches with advanced oxidation processes, such as photo- and sono-chemical technologies ${ }^{18-20}$ has been proposed as well as the use of surfactants because selective degradation is very challenging since target pollutants are entrapped in surfactant micelles. ${ }^{21}$ In the first case, the association of electrochemical oxidation with other technologies is the best choice because the concentration of pollutants becomes lower and consequently, the mass transport limitations reduce significantly the efficiency of the process $^{20,22,23}$ and it is well-known that Fenton based processes, irradiation of UV light and ultrasounds improve the mass transfer as well as active the oxidants produced electrochemically. ${ }^{22}$ Meanwhile, in the second case, selective degradation of target molecules can be observed by using low current density and high surfactant concentration because the elimination of the pollutants entrapped in micelles occurs either through the degradation of micelles followed by their

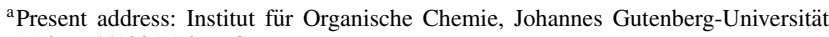
Mainz, 55128 Mainz, Germany.

zE-mail: manuel.rodrigo@uclm.es; carlosmh@quimica.ufrn.br degradation or by oxidation of free (extra-micellar) compounds as well as the production of oxidants electrochemically generated from the ions released by the surfactant degradation..$^{21,24,25}$

Therefore, the objective of this work was to investigate the treatment of effluents generated by soil-washing polluted with atrazine by using photolysis, sonolysis, electrolysis as well as photo- and sonoelectrochemical technologies using BDD anodes, focusing in the effect of the emulsion particle size and the behavior of different concentrations of surfactant used in the soil washing process. To accomplish this objective, two synthetic effluents were produced by washing a soil spiked with atrazine with well-known amounts of sodium dodecyl sulfate (SDS). The use of SDS favors an efficient elimination of organic pollutants from soil as well as the surfactant may produce sulfate during its degradation, which promotes the electrogeneration of persulfate at BDD anode, acting as an auxiliary reagent to depollute effluents. ${ }^{26}$

\section{Materials and Methods}

Chemicals.-Kaolinite was selected as model soil. This material is not reactive and it has a low hydraulic conductivity, low cation exchange capacity and zero organic content. The atrazine was chosen as a model organic compound ( $98 \%$ of purity, Sigma-Alcrich). Sodium dodecyl sulfate (SDS) was used as a model-solubilizing agent (supply by Panreac). $\mathrm{NaHCO}_{3}(96 \%)$ was also obtained from Panreac. Acetonitrile HPLC grade (a.r., Sigma-Aldrich, Spain) was used as mobile phase. Double deionized water (Millipore Milli-Q system, resistivity $=18.2 \mathrm{M} \mathrm{cm}$ at $25^{\circ} \mathrm{C}$ ) was used to prepare all solutions.

Apparatus and analysis procedures.-All samples extracted from electrolyzed solution were filtered with Whatman $0.45 \mathrm{~m}$ nylon filters before analysis. The atrazine concentration in the liquid phase was determined by using a liquid-liquid extraction process, which was carried out in separator flasks of $100 \mathrm{dm}^{3}$ using ethyl acetate/hexane as extraction solvent (ratio atrazine solution/solvent $=0.33 \mathrm{v} / \mathrm{v}$ ). The concentration of the compounds was quantified by HPLC (Agilent 1100 series) using analytical column Phenomenex Gemini $5 \mu \mathrm{m} \mathrm{C} 18$. The detection wavelength of $223 \mathrm{~nm}$ was used and the temperature oven was maintained at $25^{\circ} \mathrm{C}$. $20 \mu \mathrm{L}$ aliquots were injected, using as mobile phase, a mixture of acetonitrile/water $(45: 55(\mathrm{v} / \mathrm{v}))$ at $0.3 \mathrm{~cm}^{3}$ $\mathrm{min}^{-1}$. The total organic carbon (TOC) concentration was monitored using a Multi N/C 3100 Analytik Jena analyser. COD measurements 
were performed during electrolysis using a HACH DR2000 analyzer. Zeta potential was also measured for the clarified liquid using a Zetasizer Nano ZS (Malvern, UK). Measurements of $\mathrm{pH}$ were carried out with an InoLab WTW pH-meter. The particle size was monitored during electrochemical oxidation with an analyzer acquired from Malvern (Mastersizer Hydro 2000SM). The colorimetric method used to determine the concentration of the SDS surfactant was reported by Jurado and co-workers. ${ }^{27}$

Preparation soil washing effluent.-Samples of polluted soil $(1000 \mathrm{~g})$ were prepared by dissolving atrazine in hexane and then mixing this atrazine/hexane solution with kaolinite. The spiked clay was aerated during 1 day to favor evaporation of the hexane and, in this way; the atrazine was homogeneously distributed on the clay surface. The resulting atrazine concentration in the soil was around $100 \mathrm{mg} \mathrm{kg}^{-1}$ of soil. The preparation of surfactant-aided soil washing (SASW) remediation process was carried out in a stirred batch tank. The tank volume was $800 \mathrm{~cm}^{3}$. Low-permeability soil polluted with $100 \mathrm{mg}$ atrazine $\mathrm{kg}^{-1}$ of soil and $800 \mathrm{~cm}^{3}$ of solubilizing agent (containing deionized water, different amounts of surfactant $\left(100\right.$ and $\left.5000 \mathrm{mg} \mathrm{dm}^{-3}\right)$ and $500 \mathrm{mg} \mathrm{dm}{ }^{-3}$ of $\mathrm{NaHCO}_{3}$ ) were mixed in the reactor for $6 \mathrm{~h}$ at a stirring rate of $120 \mathrm{rpm}$. The same tank then acted as a settler (during $24 \mathrm{~h}$ ) to separate the soil from the effluent. These effluents consisted of aqueous mixtures of atrazine and surfactants with higher COD content.

Bulk degradation of the soil washing effluents with electrolysis, photolysis, sonolysis, sonoelectrolysis and photoelectrolysis.Electrochemical oxidation experiments were carried out in a benchscale plant with a single-compartment in the electrochemical flow cell. BDD and steel electrodes were used as anode and cathode, respectively. Both electrodes were circular (100 mm diameter) covering a geometric area of $78 \mathrm{~cm}^{2}$. The interelectrode gap was about $9 \mathrm{~mm}$. One of the covers of this cell was made of quartz in order UV light to access into the reaction media. A UV lamp VL-215MC (Vilber Lourmat), $\lambda=254 \mathrm{~nm}$, intensity of $930 \mathrm{~W} / \mathrm{cm}^{2}$ and energy $4.43-6.20 \mathrm{eV}$ irradiating $15 \mathrm{~W}$ directly to the quartz cover, as reported elsewhere. $^{20,28}$ The ultrasound generator was a UP200S (Hielscher Ultrasonics $\mathrm{GmbH}$, Germany) equipped with a titanium glass horn of $40 \mathrm{~mm}$ diameter, length $100 \mathrm{~mm}$, emitting $24 \mathrm{kHz}$ and maximum ultrasonic power $200 \mathrm{~W} .^{29}$ For the electrochemical flow cell, inlet and outlet were provided for effluent circulation through the reactor; the simulated effluent was stored in a thermos-regulated glass tank and circulated through the cell using a peristaltic pump at a flow rate of $160 \mathrm{dm}^{3} \mathrm{~h}^{-1}$. The electrical current was applied using a DC Power Supply (FA-376 PROMAX) and thermostated (Digiterm 100, JP Selecta, Barcelona, Spain) by means of a water bath, which allowed

\section{Table I. Characteristic of the effluents produced by SASW} approach.

\begin{tabular}{lll} 
& Effluent 1 & Effluent 2 \\
\hline Surfactant/soil ratio $\left(\mathrm{mg} \mathrm{SDS} \mathrm{kg}^{-1}\right.$ soil) & 0.08 & 4.00 \\
COD $\left(\mathrm{mg} \mathrm{dm}^{-3}\right)$ & 276 & 1290 \\
TOC $\left(\mathrm{mg} \mathrm{dm}^{-3}\right)$ & 40.89 & 667 \\
Mean particle size $(\mu \mathrm{m})$ & 1100 & 178 \\
z-potential $(\mathrm{mV})$ & -24.9 & -51
\end{tabular}

the temperature to be maintained at the desired set point $\left(25^{\circ} \mathrm{C}\right)$. The electro-oxidation was carried out galvanostatically using $0.70 \mathrm{dm}^{3}$ of a solution containing $100 \mathrm{mg} \mathrm{dm}^{-3}$ atrazine and two different concentrations of SDS 100 and $5000 \mathrm{mg} \mathrm{dm}^{-3}$.

\section{Results and Discussion}

One of the most efficient technologies for removing low solubility pesticides from soil is by washing soil with surfactant fluids. This process (usually known as surfactant-aided soil washing, SASW) transfers the pollutants from the soil to the washing fluid, which becomes wastewater from that moment and it needs for further treatment in order to complete the remediation of the pollutant. Characteristic of wastewaters depend importantly on the ratio surfactant/soil as showed in Table I.

After the soil washing process, concentration of atrazine in the soil was negligible (> $1 \mathrm{mg} \mathrm{kg}^{-1}$ soil (HPLC determination)). This low value indicated that SASW approach is efficient to transfer completely the atrazine contained in the soil to the wastewater. However, higher efficiency on the transfer was achieved when a lower dose of surfactant was used.

In comparing the two effluents, it can be observed that the effluent of treatment 2 (with a higher concentration of surfactant in the washing fluid) presented higher COD and TOC values but the size of the particles was smaller as well as the superficial charge of them was considerably negative. Additionally, the most important pollutant was the surfactant which was approximately 40 times more concentrated than atrazine. Conversely, in the effluent of treatment 1 , the mass concentration was very similar between the atrazine and the surfactant. This means that different results can be expected when both effluents will be treated by electrochemical technologies.

The performance of the electrochemical assisted-technologies studied in this work was compared by using the most common operation conditions typically reported in the literature about the electrochemical oxidation of wastes polluted with pesticides (current density: $30 \mathrm{~mA} \mathrm{~cm}{ }^{-2}$; temperature: $25^{\circ} \mathrm{C}$; surface/volume ratio $0.1 \mathrm{dm}^{-1}$; UV
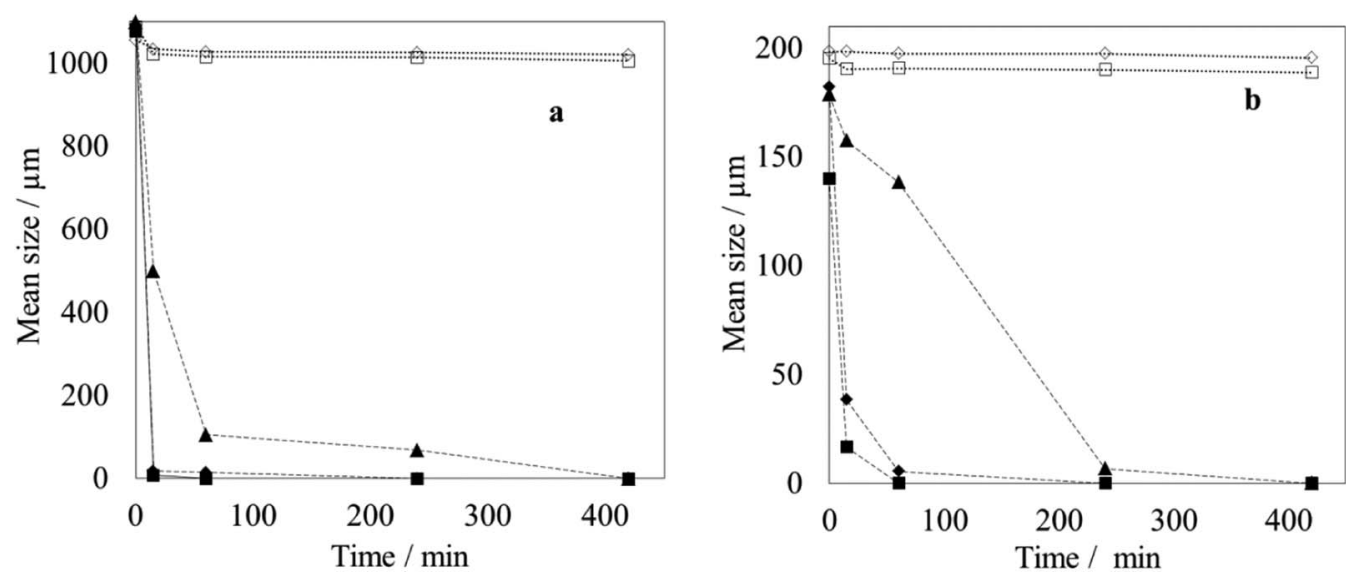

Figure 1. Changes in the mean-size of micelles during the electrolysis $(\boldsymbol{\Lambda})$, sonoelectrolysis $(\diamond)$, photoelectrolysis $(\boldsymbol{\square})$, sonolysis $(\diamond)$ and photolysis $(\square)$ of soil washing effluents obtained with ratio surfactant/soil of $0.08 \mathrm{mg} \mathrm{SDS} / \mathrm{Kg}$ soil (a) and $4.00 \mathrm{mg}$ SDS $/ \mathrm{Kg}$ soil (b). 

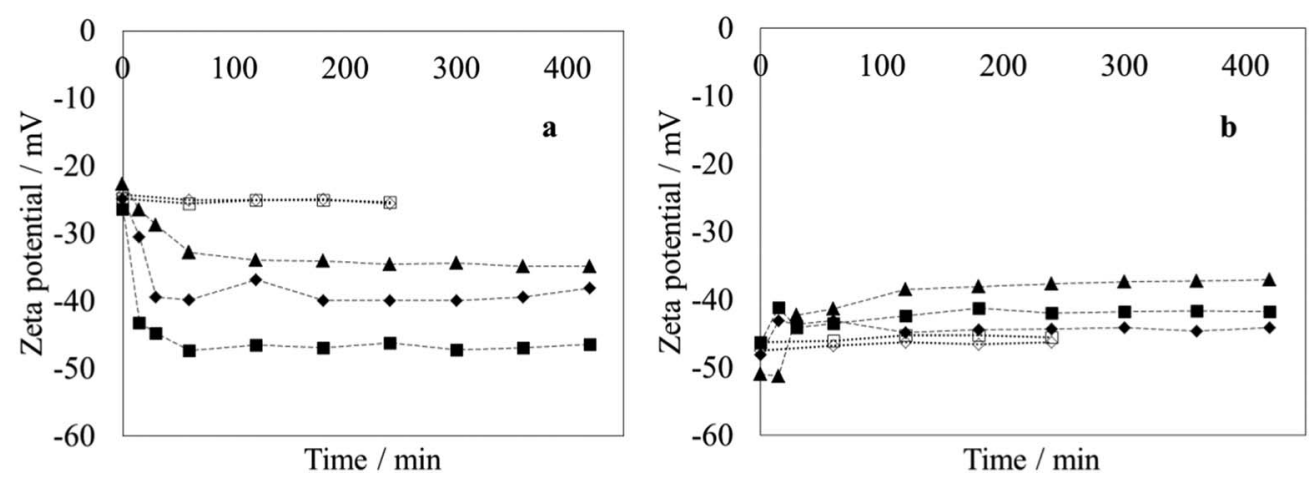

Figure 2. Changes in the z-potential during the electrolysis electrolysis ( $\mathbf{\Lambda})$, sonoelectrolysis $(\bullet)$, photoelectrolysis $(\square)$, sonolysis $(\diamond)$ and photolysis $(\square)$ of soil washing effluents obtained with ratio surfactant/soil of $0.08 \mathrm{mg} \mathrm{SDS} / \mathrm{Kg}$ soil (a) and $4.00 \mathrm{mg} \mathrm{SDS} / \mathrm{Kg}$ soil (b).

irradiation: $254 \mathrm{~nm}$ and $930 \mathrm{~W} \mathrm{~cm}^{-2}$ with 4.43-6.20 $\mathrm{eV}$ irradiating $15 \mathrm{~W}$; US irradiation $24 \mathrm{kHz}$, with $200 \mathrm{~W}$ ). Thus, Fig. 1 illustrates the particle size variation when the soil-washing effluent polluted with atrazine/SDS was treated by using electrolysis, photolysis, sonolysis, photoelectrolysis and sonoelectrolysis.

As it can be observed, particle sizes decreased during the treatment till their complete depletion by using electrolysis, photoelectrolysis and sonoelectrolysis as treatment methods (Fig. 1). In single electrolysis, the decrease appears to fit a linear rather than exponential shape, with two different slopes (1600-400)/7.3 $\mu \mathrm{m} / \mathrm{min}$ for mean particle size over $400 \mu \mathrm{m}$ and $200 / 20 \mu \mathrm{m} / \mathrm{min}$ for smaller particles. This later slope was the same for both tests. In comparing these three technologies studied, the decrease on the particle size was significantly efficient when irradiated tests (light and US) were associated to electrolysis than in single approach. Initially, mechanisms expected in both treatments were completely different. By using US irradiation, it was expected an increase in the turbulence and consequently, lower limitations in direct electrolytic process should be observed. However, only decomposition of labile oxidants (if any) to radical species can be expected due to the low frequency used $(24 \mathrm{kHz})$, but no formation of hydroxyl radicals from water decomposition is feasible. Another interesting feature was that, cavitation phenomena could be attained; promoting the fragmentation of atrazine molecules, and consequently, it favored the elimination of atrazine from the wastewater. Conversely, with UV light irradiation, mass transfer cannot be improved because a massive formation of radical species is expected. In fact, the results demonstrated that the production of oxidants by UV irradiation coupled to electrolysis favored the degradation of surfactant and atrazine in the effluents (discussed below). It is important to indicate that, no significant effect was achieved when sonolysis and photolysis were employed. This behavior indicates that, single technologies did not produce the enough amounts of oxidants to favor the elimination of pollutants in the soil washing effluents.

On the other hand, it was note that, the micelles in the soil washing effluent consists of microdrops of atrazine surrounded by SDS molecules with negative sulfonic group facing the water. It should be indicated by the surface charge of micelles, which was measured by z-potential technique. In fact, the higher the concentration of SDS molecules in the micelles, the more negative was the resulting charge (Fig. 2). At this point, it means that attack to the micelles will be an important parameter about the mechanisms of oxidation.

Different changes were observed in the tests carried out. More negative z-potential values were observed when the effluent 1 was treated, suggesting that the decrease in size of the micelles was followed by a reorientation of the SDS, making the new smaller particles more negative. ${ }^{30}$ Conversely, more positive z-potential values was measured when effluent 2 (with a higher SDS/soil ratio) was treated; indicating that the particles become less negative in their surface than those contained in the raw washing fluid when the treatment was started. Then, the type of charge in the particles during the treatment with three technologies (electrolysis, photoelectrolysis and sonoelectrolysis) depended only on the waste treated. In the end of the treatments, similar Z-potential values were achieved ranging from -40 to $-50 \mathrm{mV}$. The most important observation was the less negative value attained by the electrolytic treatment, which may indicate a more efficient depletion of the SDS from the micelles. In the case of sonolysis and photolysis, no important alteration on the charge of particles was observed, indicating that the micelles formed were not degraded by using these approaches due to the lower amount of oxidants produced.

Once characterized the changes in the micelles atrazine-SDS, it is important to focus on the changes in the concentration of both species during the treatment of the soil washing wastes when electrolysis, photoelectrolysis and sonoelectrolysis were applied. Fig. 3 shows the
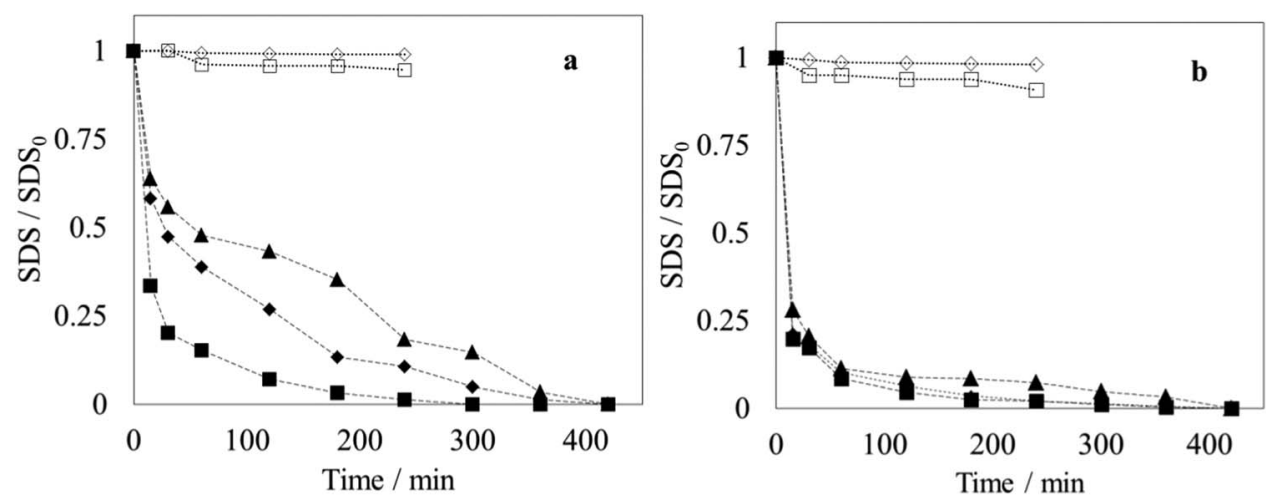

Figure 3. Changes in the SDS concentration during the electrolysis $(\boldsymbol{\Lambda})$, sonoelectrolysis $(\bullet)$, photoelectrolysis $(\square)$, sonolysis $(\diamond)$ and photolysis $(\square)$ of soil washing effluents obtained with ratio surfactant/soil of $0.08 \mathrm{mg} \mathrm{SDS} / \mathrm{Kg}$ soil (a) and $4.00 \mathrm{mg} \mathrm{SDS} / \mathrm{Kg}$ soil (b). 


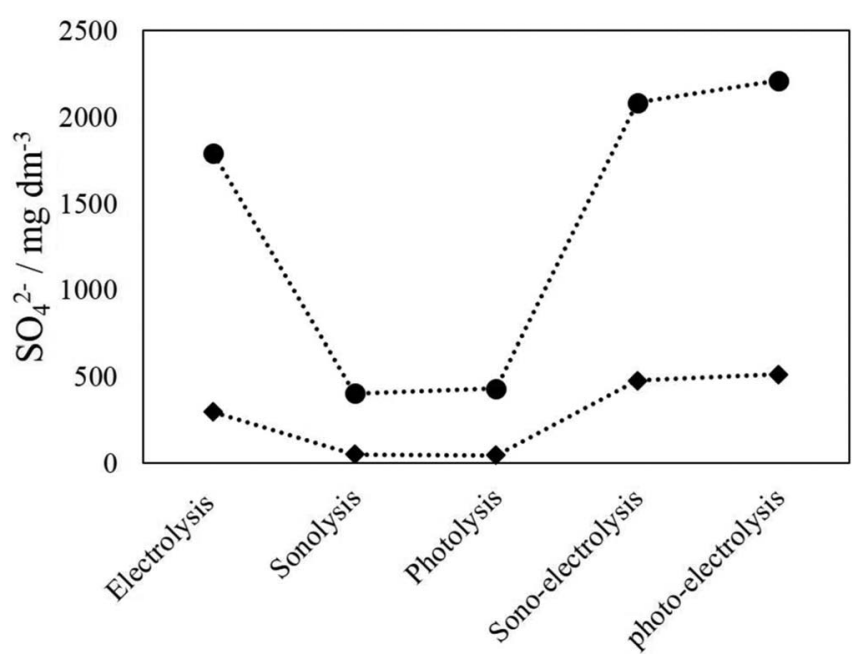

Figure 4. Changes in the sulfate concentration during the electrochemical treatment of washing effluents: $100 \mathrm{mg} \mathrm{dm}^{-3}(\boldsymbol{})$ and $5000 \mathrm{mg} \mathrm{dm}^{-3}(\mathbf{O})$ of surfactant.

changes in the concentration of the surfactant SDS during the electrolysis of the two soil-washing wastes studied in this work (obtained after washing the soil with 100 and $5000 \mathrm{mg} \mathrm{dm}^{-3}$ SDS solution). A complete oxidation of the surfactant was attained by applying electrolysis, photoelectrolysis and sonoelectrolysis, at both effluents. This fact clearly indicated that severe oxidation conditions during the treatment of the waste with the three technologies were accomplished. Meanwhile, different conclusions can be established when a comparison of the these technologies is performed. For sonolysis and photolysis, no degradation of SDS was achieved. In the case of photo-electrolysis, the results clearly demonstrated that this was the most efficient technology for treating different effluents with lower and higher concentrations of SDS. Additionally, in comparing the treatment of the two wastes, the effluent with high concentrations of SDS was efficiently depolluted by using electrolysis, photoelectrolysis and sonoelectrolysis, achieving slight performance differences between them. Conversely, the effect on the efficiency of photoelectrolysis was very important when the effluent polluted with low concentrations of SDS was treated.

In order to explain the differences observed, it has to be taken into account that the concentration of SDS used. The oxidation of SDS allowed to release sulfates in solution, which are precursors in the formation of persulfates during the treatment. ${ }^{31}$ The occurrence of these powerful oxidants was the key to understand the differences between the processes. In a reaction system with organics, it has no sense to determine the concentration of persulfates because these oxidants react rapidly with the pollutants. However, the concentration of sulfate (shown in Fig. 4 as the maximum concentration obtained) is an indicator of the possible formation of these species. As can be observed in Fig. 4, a significant concentration of sulfate was determined when electrolysis, photoelectrolysis and sonoelectrolysis were applied. This behavior indicates that, SDS molecule was fragmented and after that, an important amount of sulfate ion was released in the effluent, then, these ions were oxidized at BDD surface, favoring the production of persulfates. ${ }^{26}$ In fact, this novel mechanism was already confirmed by Araújo and co-workers ${ }^{26}$ and similar mechanisms was supposed by Trellu. ${ }^{21}$ However, persulfates were also activated by US or UV irradiation to produce sulfate radicals, ${ }^{22}$ degrading efficiently the pollutants in the effluent.

As showed in Fig. 5, a complete removal of the pesticide, below detectable concentrations by HPLC, was accomplished. However, except for the photo-electrolysis which attained comparable efficiencies for both wastes (100\% of atrazine elimination after $250 \mathrm{~min}$ (Fig. 5)); the treatment of the waste polluted with a higher concentration of SDS seems to be more efficient with electrolysis and sonoelectrolysis. Another feature is that a complete removal of atrazine was attained for current charge applied after $400 \mathrm{~min}$ (Fig. 5) by using electrolysis and sonoelectrolysis. These behaviors can be also explained with the formation of persulfates. Higher SDS concentrations in the waste may lead to higher concentrations of $\mathrm{S}_{2} \mathrm{O}_{8}{ }^{2-}$ from $\mathrm{SO}_{4}{ }^{2-}$ ions $\left(2 \mathrm{SO}_{4}{ }^{2-}\right.$ $\left.\rightarrow \mathrm{S}_{2} \mathrm{O}_{8}{ }^{2-}+2 \mathrm{e}^{-}\right)^{20,22,26,30,31}$ on BDD surface, after SDS breaking structure. ${ }^{26}$ It contributed to complete the degradation of remaining atrazine as well as part of the organic surfactant. Hydroxyl radical $\left(\mathrm{BDD}\left({ }^{\bullet} \mathrm{OH}\right)\right)$ formed from water discharge on BDD surface from reaction: $\mathrm{H}_{2} \mathrm{O} \rightarrow \cdot \mathrm{OH}+\mathrm{e}^{-}+\mathrm{H}^{+}, 32$ may also be considered the responsible species for the electrochemical combustion of organic pollutants in the emulsion. ${ }^{22,24,25}$ One important point to explain the better performance of the photolectrolysis and sonoelectrolysis in the waste with lower concentration of SDS, it was that activation of persulfate by US or UV irradiation ${ }^{20,22}$ leads to the production of radical sulfate, which is more effective in the oxidation than the persulfate. However, the activation by UV irradiation is more efficient. These assertions are confirmed by the behavior observed at sonolysis and photolysis, where no activation of persulfates was achieved because no enough amount of persulfate was produced and no BDD electrolysis was used. Also, the kinetic constants obtained for removing atrazine and SDS from effluents confirmed the efficiency of sonoelectrolysis and photoelectrolysis treatments (Fig. 6).

Figs. 7 and 8 showed the values of changes in the values of the TOC and COD during the tests carried out to the two washing-fluids. Total mineralization (Fig. 7) and oxidation (Fig. 8) of organic matter in the effluents were achieved by using electrolysis, photoelectrolysis and sonoelectrolysis regardless of its initial composition of the waste and differences between technologies. For electrolysis when the effluent 1 was treated (Fig. 7a), it was observed that after $20 \mathrm{~min}$, TOC decayed about $60 \%$ but, a plateau behavior was observed between 20 and $80 \mathrm{~min}$. For sonoelectrolysis, $80 \%$ of TOC removal was attained after $30 \mathrm{~min}$ of treatment of the effluent 1 , subsequently, the elimination was slowly achieved until $250 \mathrm{~min}$. Similar effects were
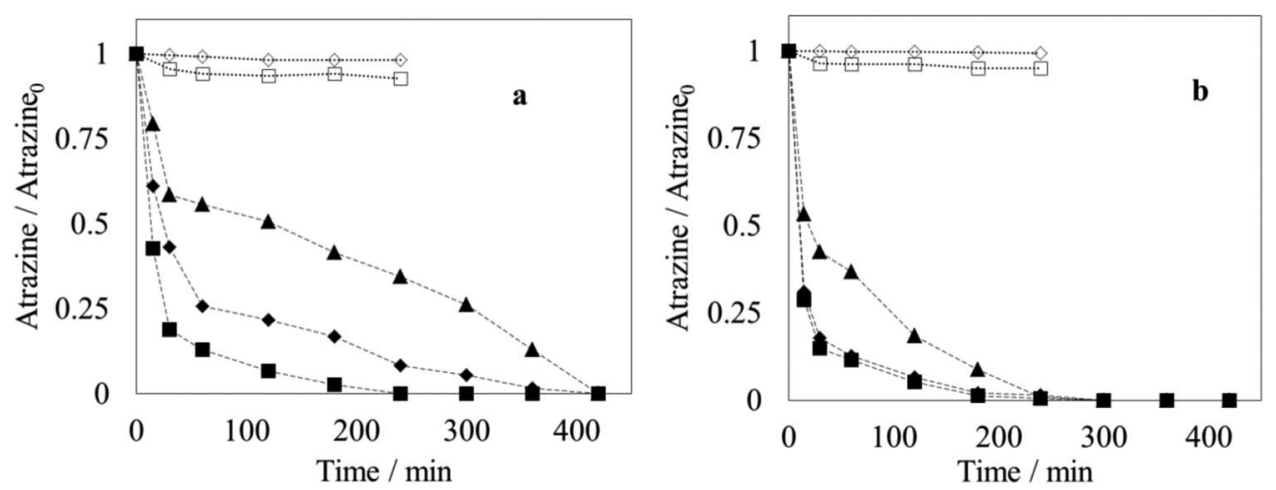

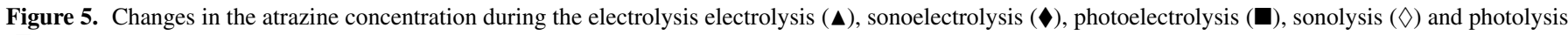
( $\square$ ) of soil washing effluents obtained with ratio surfactant/soil of $0.08 \mathrm{mg} \mathrm{SDS} / \mathrm{Kg}$ soil (a) and $4.00 \mathrm{mg}$ SDS /Kg soil (b). 


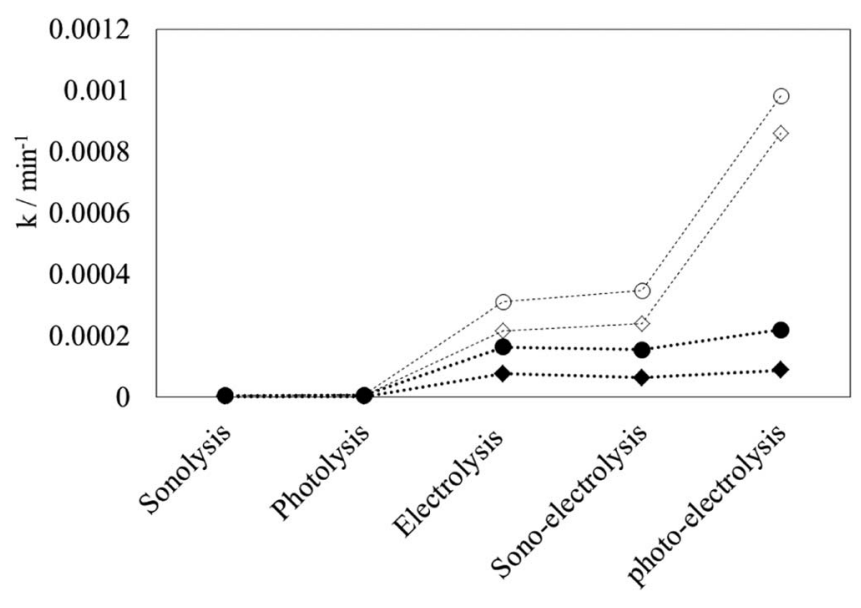

Figure 6. Kinetic constants (k) in the oxidation (empty symbols, in terms of COD) and mineralization (full symbols, in terms of TOC) of Atrazine (diamonds) and SDS (circles) by concentration SDS 100 (full symbols) and 5000 (empty symbols) $\mathrm{mg} \mathrm{dm}^{-3}$ of soil washing effluents.

observed for COD removals at electrolysis and sonoelectrolysis. This behavior can be due to the formation of intermediates that are difficult to degrade when electrolysis and sonoelectrolysis approaches are applied (Fig. 7a), even when these byproducts were gradually degraded until their complete mineralization (in fact, HPLC results expressed in terms of chromatographic areas confirm that a significant amount of intermediates are produced at electrolysis and sonoelectrolysis, see Fig. 9). Conversely, a rapid mineralization was initially accomplished by photoelectrolysis (Fig. 7a), which was completed after $100 \mathrm{~min}$ for the effluent 1 . In fact, no significant amount of byproducts is produced, favoring the mineralization of the organic matter (Fig. 9).

Fig. $7 \mathrm{~b}$ also showed TOC values as a function of time, observing that the removal of organic matter was quickly removed after $50 \mathrm{~min}$ from effluent 2 , after that, the elimination was gradual due to the mass transport conditions. These figures are related to the production of persulfate when surfactant molecules were broken, releasing sulfate ions in solution. Subsequently, synergistic effects of sonication and irradiating photo-electrolysis light were clearly observed in the oxidation rate due to the improvement of mass transfer to the conductive-diamond surface in the case of sonoelectrolysis and to the promotion of the formation of radicals in the bulk solution from oxidants produced electrochemically in the case UV light. These oxidant species (persulfates) together with the ${ }^{\bullet} \mathrm{OH}$ radicals can favor the removal of organic matter through the mediated oxidation. It is important to remark that, no significant elimination was observed at sonolysis and photolysis technologies because no efficient formation of oxidants was attained. Then, these approaches were not efficient to be applied for treating this kind of effluents.

\section{Conclusions}

From this work, the following conclusions can be drawn:

Combination of soil washing and electrochemical advanced oxidation technologies based on diamond electrodes was a very efficient method for the depletion of atrazine from polluted soils and effluents generated,

Characteristics of the effluent produced in soil washing treatments were strongly influenced by the ratio surfactant/soil used, however, SDS was a good auxiliary reagent to remove pesticides from soil and it contributed when BDD-based technologies were used for degrading the effluent produced,
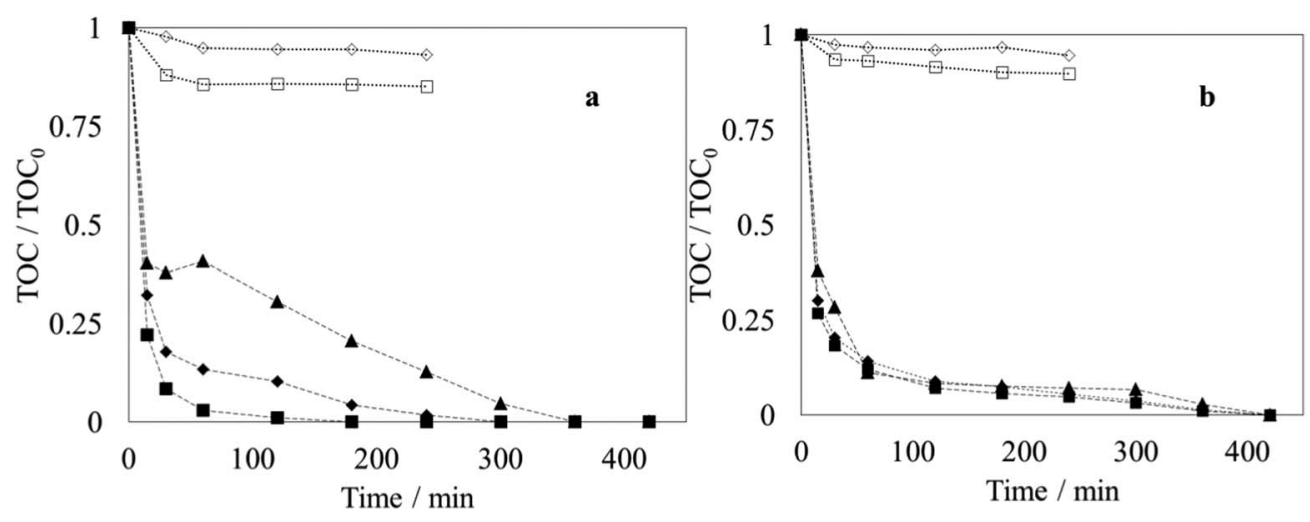

Figure 7. Changes in the TOC during the electrolysis electrolysis $(\boldsymbol{\Lambda})$, sonoelectrolysis $(\bullet)$, photoelectrolysis $(\square)$, sonolysis $(\diamond)$ and photolysis $(\square)$ of soil washing effluents obtained with ratio surfactant/soil of $0.08 \mathrm{mg}$ SDS/Kg soil (a) and $4.00 \mathrm{mg}$ SDS $/ \mathrm{Kg}$ soil (b).
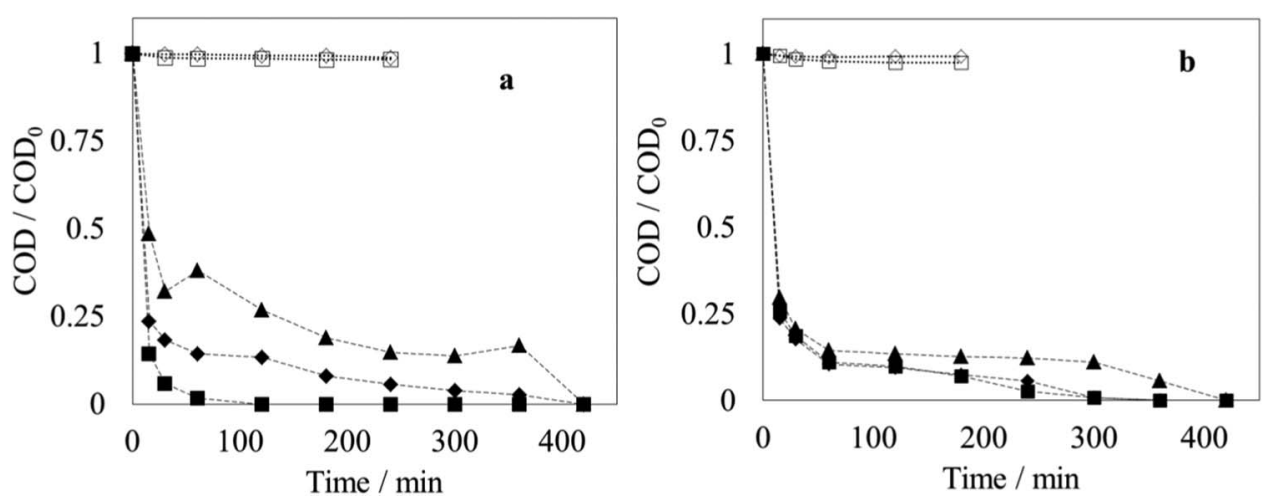

Figure 8. Changes in the COD during the electrolysis electrolysis $(\boldsymbol{\Delta})$, sonoelectrolysis $(\bullet)$, photoelectrolysis $(\boldsymbol{\square})$, sonolysis $(\diamond)$ and photolysis $(\square)$ of soil washing effluents obtained with ratio surfactant/soil of $0.08 \mathrm{mg} \mathrm{SDS} / \mathrm{Kg}$ soil (a) and $4.00 \mathrm{mg}$ SDS /Kg soil (b). 


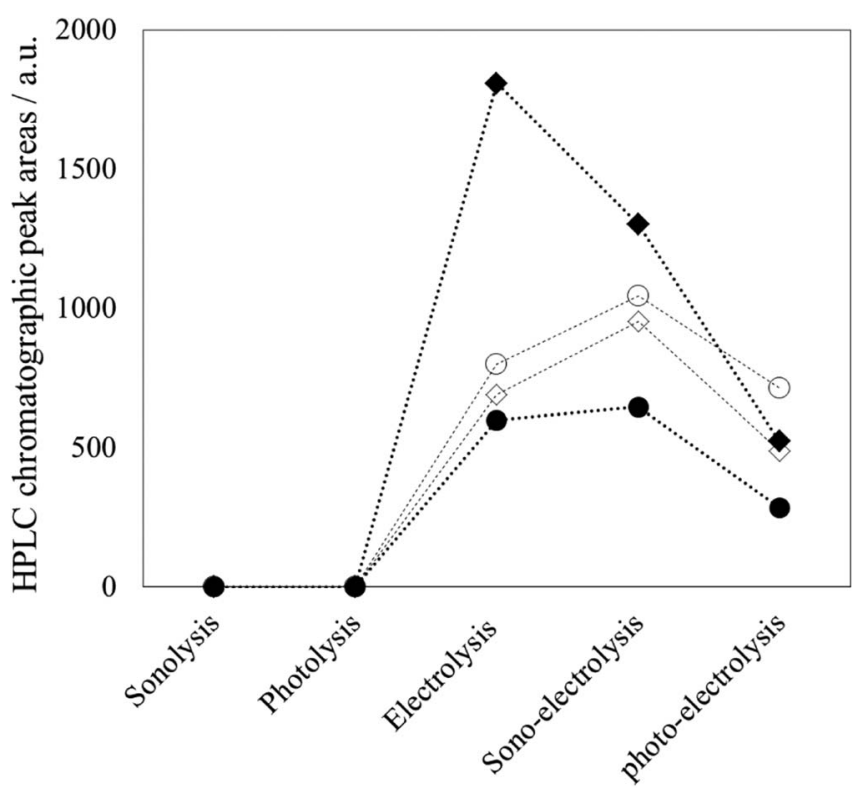

Figure 9. Main intermediates detected during treatment soil washing effluents. Intermediate $1(\diamond)$ and intermediate $2(\bullet)$. Full symbol: $100 \mathrm{mg} \mathrm{dm}^{-3}$ of SDS; Empty symbol: $5000 \mathrm{mg} \mathrm{dm}^{-3}$.

The mean particle size indicated the formation of micelles which were fragmented when sonoelectrolysis, photoelectrolysis and electrolysis were used as treatment processes, indicating that oxidation mechanisms involved the attack of oxidants to the surface of micelles,

Electrolysis with diamond electrodes of the waste produced in the soil washing was very efficient and it attained the total depletion of pollutants by mineralization, but it was less efficient than photoelectrolysis and sonoelectrolysis approaches,

Persulfate produced by oxidation of the sulfate released, during the oxidation of SDS, played an important role in the oxidation mechanisms of this type of pollutants, and it can be proposed as an auxiliary reagent to be introduced in the effluent to increase the efficiency of the electrochemical approach used by trapping pollutants as well as by producing persulfates. Even if the SDS is itself a pollutant, it can be completely removed after its active participation in the process.

\section{Acknowledgments}

The authors acknowledge funding support from the EU and Spanish Government through the MINECO Project CTM2013-45612-R, FEDER 2007-2013 PP201010 (Planta Piloto de Estación de Estación de Regeneración de Aguas Depuradas) and INNOCAMPUS. Financial support from National Council for Scientific and Technological Development (CNPq - 465571/2014-0; CNPq - 446846/2014-7 and CNPq - 401519/2014-7) and FAPESP (2014/50945-4) are gratefully acknowledged. Brazil government by grant for $\mathrm{PhD}$ fellowship scholarship given for "doutorado sanduiche" under "Ciências sem Fronteiras" program to develop the experimental research at the UCLM-Spain is gratefully acknowledged. Carlos A. Martínez-Huitle acknowledges the funding provided by the Alexander von Humboldt Foundation (Germany) and Coordenação de Aperfeiçoamento de Pessoal de Nível Superior (Brazil) as a fellowship for Experienced Researcher (88881.136108/2017-01) at the Johannes GutenbergUniversität Mainz, Germany.

\section{ORCID}

E. Vieira dos Santos (D) https://orcid.org/0000-0003-2189-5694

C. A. Martínez-Huitle (ID https://orcid.org/0000-0002-6209-5426

\section{References}

1. M. A. Rodrigo, N. Oturan, and M. A. Oturan, Chem. Rev., 114, 8720 (2014).

2. Z. Lin, J. R. Roede, C. He, D. P. Jones, and N. M. Filipov, Toxicology, 326, 130 (2014).

3. G. R. P. Malpass, D. W. Miwa, R. L. Santos, E. M. Vieira, and A. J. Motheo, Env. Chem. Lett., 10, 177 (2012).

4. A. B. Ribeiro, J. M. Rodriguez-Maroto, E. P. Mateus, and H. Gomes, Chemosphere, 59, 1229 (2005)

5. Y. Zhang, Y. Li, and X. Zheng, Sci. Total Env., 409, 625 (2011).

6. M. Mascia, A. Vacca, S. Palmas, and A. M. Polcaro, J. Appl. Electrochem., 37, 71 (2007).

7. N. Oturan, E. Brillas, and M. A. Oturan, Env. Chem. Lett., 10, 165 (2012).

8. B. Balci, M. A. Oturan, N. Oturan, and I. Sires, J. Agr. Food Chem., 57, 4888 (2009).

9. W. Chu, K. H. Chan, and N. J. D. Graham, Chemosphere, 64, 931 (2006).

10. C. A. Pineda Arellano, A. Jimenez Gonzalez, S. Silva Martinez, I. Salgado-Transito, and C. Perez Franco, J. Photoch. Photobio. A., 272, 21 (2013).

11. G. R. P. Malpass, D. W. Miwa, L. Gomes, E. B. Azevedo, W. F. D. Vilela, M. T. Fukunaga, J. R. Guimaraes, R. Bertazzoli, S. A. S. Machado, and A. J. Motheo, Water Sci. Technol., 62, 2729 (2010).

12. B. Balci, N. Oturan, R. Cherrier, and M. A. Oturan, Water Res., 43, 1924 (2009)

13. G. R. P. Malpass, D. W. Miwa, S. A. S. Machado, P. Olivi, and A. J. Motheo, J. Hazard. Mater., 137, 565 (2006).

14. G. R. P. Malpass, G. R. Salazar-Banda, D. W. Miwa, S. A. S. Machado, and A. J. Motheo, Environ. Technol., 34, 1043 (2013).

15. G. R. P. Malpass, D. W. Miwa, S. A. S. Machado, and A. J. Motheo, J. Hazard. Mater, 180, 145 (2010).

16. F. Zaviska, P. Drogui, J.-F. Blais, G. Mercier, and P. Lafrance, J. Hazard. Mater, 185 , 1499 (2011).

17. A. Beatriz Baranda, O. Fundazuri, and I. Martinez de Maranon, J. Photoch. Photobio. A., 286, 29 (2014).

18. M. J. Martin de Vidales, S. Barba, C. Saez, P. Canizares, and M. A. Rodrigo, Electrochim. Acta, 140, 20 (2014)

19. F. L. Souza, C. Saez, P. Canizares, A. J. Motheo, and M. A. Rodrigo, Appl. Catal. B-Environ., 144, 121 (2014).

20. C. A. Martínez-Huitle, M. A. Rodrigo, I. Sirés, and O. Scialdone, Chem. Rev, 115, 13362 (2015)

21. C. Trellu, N. Oturan, Y. Pechaud, E. D. van Hullebusch, G. Esposito, and M. A. Oturan, Water Res., 118, 1 (2017).

22. I. Sirés, E. Brillas, M. A. Oturan, M. A. Rodrigo, and M. Panizza, Environ. Sci. Pollut. Res., 14, 8336 (2014).

23. J. H. B. Rocha, A. M. S. Solano, N. S. Fernandes, D. R. da Silva, J. M. Peralta-Hernandez, and C. A. Martínez-Huitle, Electrocatalysis, 3, 1 (2012).

24. C. Trellu, O. Ganzenko, S. Papirio, Y. Pechaud, N. Oturan, D. Huguenot, E. D. van Hullebusch, G. Esposito, and M. A. Oturan, Chem. Eng. J., 306, 588 (2016).

25. C. Trellu, E. Mousset, Y. Pechaud, D. Huguenot, E. D. van Hullebusch, G. Esposito, and M. A. Oturan, J. Hazard. Mater, 306, 149 (2016).

26. K. C. F. Araújo, J. P. P. Barreto, J. C. Cardozo, E. V. Santos, D. M. Araújo, and C. A. Martínez-Huitle, Environ. Chem. Lett., 1 (2018).

27. E. Jurado, M. Fernandez-Serrano, J. Nunez-Olea, G. Luzon, and M. Lechuga, Chemosphere, 65, 278 (2006).

28. F. d. L. Souza, C. Saez, P. Canizares, A. d. J. Motheo, and M. Andres Rodrigo, J. Chem. Technol. Biot., 89, 1251 (2014).

29. F. L. Souza, C. Saez, P. Canizares, A. J. Motheo, and M. A. Rodrigo, Ind. Eng. Chem. Res., 52, 9674 (2013).

30. E. V. D. Santos, C. Sáez, C. A. Martínez-Huitle, P. Cañizares, and M. A. Rodrigo, Electrochem. Commun., 55, 26 (2015).

31. J. P. de, P. Barreto, K. C. de, F. Araújo, D. M. de Araújo, and C. A. Martínez-Huitle, ECS Electrochem. Lett., 4, E9 (2015).

32. C. do N. Brito, D. R. da Silva, S. Garcia-Segura, D. C. de Moura, and C. A. Martínez-Huitle, J. Electrochem. Soc., 163, E62 (2016). 